\title{
Scenario Analyses of Land Use Conversion in the North China Plain: An Econometric Approach
}

\author{
Jinyan Zhan, ${ }^{1}$ Feng Wu, ${ }^{1}$ Chenchen Shi, ${ }^{1}$ Fan Zhang, ${ }^{2}$ and Zhihui $\mathrm{Li}^{\mathbf{3}, 4,5}$ \\ ${ }^{1}$ State Key Laboratory of Water Environment Simulation, School of Environment, Beijing Normal University, Beijing 100875, China \\ ${ }^{2}$ School of Mathematics and Physics, China University of Geosciences (Wuhan), Wuhan 430074, China \\ ${ }^{3}$ Institute of Geographic Sciences and Natural Resources Research, Chinese Academy of Sciences, Beijing 100101, China \\ ${ }^{4}$ University of Chinese Academy of Sciences, Beijing 100049, China \\ ${ }^{5}$ Center for Chinese Agricultural Policy, Chinese Academy of Sciences, Beijing 100101, China
}

Correspondence should be addressed to Jinyan Zhan; zhanjinyan.bnu@gmail.com

Received 6 August 2013; Revised 9 October 2013; Accepted 6 November 2013

Academic Editor: Xiangzheng Deng

Copyright ( 2013 Jinyan Zhan et al. This is an open access article distributed under the Creative Commons Attribution License, which permits unrestricted use, distribution, and reproduction in any medium, provided the original work is properly cited.

\begin{abstract}
Scenario analysis and dynamic prediction of land use structure which involve many driving factors are helpful to investigate the mechanism of land use changes and even to optimize land use allocation for sustainable development. In this study, land use structure changes during 1988-2010 in North China Plain were discerned and the effects of various natural and socioeconomic driving factors on land use structure changes were quantitatively analyzed based on an econometric model. The key drivers of land use structure changes in the model are county-level net returns of land resource. In this research, we modified the net returns of each land use type for three scenarios, including business as usual (BAU) scenario, rapid economic growth (REG) scenario, and coordinated environmental sustainability (CES) scenario. The simulation results showed that, under different scenarios, future land use structures were different due to the competition among various land use types. The land use structure changes in North China Plain in the 40-year future will experience a transfer from cultivated land to built-up area, an increase of forestry, and decrease of grassland. The research will provide some significant references for land use management and planning in the study area.
\end{abstract}

\section{Introduction}

Land use change, as the direct cause and response of regional environment change, has always been one of the core topics of global change research [1]. It is difficult to analyze the relationship between land use and climate change clearly. On the one hand, climate change should exert impacts on the production of cultivated land, forestry, grassland, and so forth. For example, agricultural yields can be directly affected by climate change through changing temperature and precipitation, the distribution of pests, and the frequency of forest fires, and the markets can also be affected by climate change [2]. Moreover, in recent years, there have been a number of literature-analyzed effects of climate change on agricultural production, with the help of some models $[3,4]$. From these pieces of literature, we can learn that hedonic price models are widely used to estimate the relationship between county-level farmland values and climate variables such as temperature and precipitation. These models are then used to simulate the effects of climate change on the value of agricultural production [5]. Even so, some researchers think that it is unreasonable to use mean temperature in the analysis of climate change impacts on agriculture [6]. They find that the grain output has a good positive correlation with temperature but then falls quickly as temperature increases above a certain threshold. Other studies support these findings for global timber productivity $[7,8]$. In most regions, crops are sensitive to climate change $[9,10]$. Usually, global warming will accelerate the crop development, alter the growing season, and enhance the maintenance respiration [11], while, as to animal husbandry development, global warming would lead to grassland degradation, which would reduce the amount of livestock grazing and then decrease the output of livestock production. Meanwhile, livestock grazing might promote the $\mathrm{CO}_{2}$ emissions [12-14]. According to the researches mentioned above, climate change will affect the 


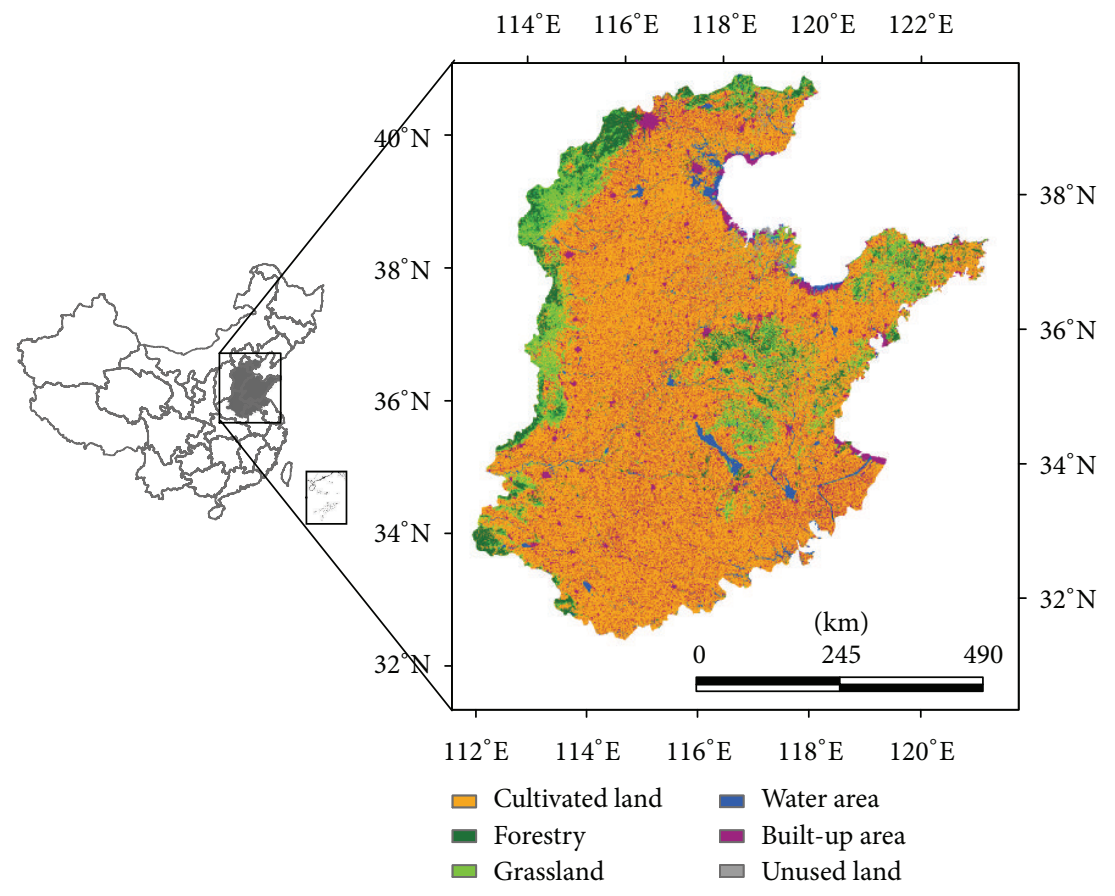

FIgURE 1: Location and land use structure of the North China Plain.

agriculture, forestry, animal husbandry production, and so forth; then, the demand for products of different land use types can result in new balance of the supply of and demand for land and further lead to land use structure changes. On the other hand, most of experts think that the climate system should take account of land use; that is, land use/cover change plays an important role in climate change; for example, afforestation and reforestation can reduce atmospheric $\mathrm{CO}_{2}$ concentrations, thus, to mitigate the emission of greenhouse gas, and deforestation can result in temperature rising and precipitation decreasing in some regions [15]. Then, through the connection of climate change, we can figure out that the land use structure has relationships with climate change.

Research on land use structure changes needs to identify the driving factors from a systemic perspective and choose an appropriate model as a tool to reflect the changes to spatial distribution on a certain scale [16]. At present, there have been some achievements in applying economic models and empirical statistical methods for analyzing the driving forces of the land use structure changes, and the simulation about land structure change has a tendency of regionalization and of being microcosmic, while there is much more room for improvement in many links of such simulation researches [17]. For example, quite a lot of case studies just simulated the changes of one or several types of land use and seldom comprehensively simulated macroscopic structural changes of all land use types from a systemic perspective [18]. The change of land use structure is a dynamic process, which should be based on regional socioeconomic development characteristics, cultural traditions, natural conditions, the previous trend of land use structure changes, and other factors to acquire valuable simulation results for decision. And it is helpful to make the forecast and evaluation results more science oriented and rational by simulating regional land use structure changes under different scenarios.

The North China Plain is located in $32-40^{\circ} 30^{\prime} \mathrm{N}, 113-$ $120^{\circ} 30^{\prime} \mathrm{E}$ (Figure 1), which belongs to the warm temperate zone, with the flat terrain, deep soil layer, and peaks and valleys of rainfall and heat in the same period. It covers seven provinces and cities, including Hebei, Henan, Shandong, Jiangsu, Anhui, Beijing, and Tianjin (containing 387 counties), and has an area of 33.4 million hectares, among which the area of land is 21 million hectares, and it is the largest plain in China [19]. The region with convenient transportation, developed industries, and sufficient labor is one of the most important agricultural regions, and its agricultural production has a great potential for development. The North China Plain is a region that was earlier developed and was greatly influenced by human activities, and it is also one of economically developed regions in China. The distribution of towns and cities is relatively intensive in the North China Plain; in addition to Beijing and Tianjin there are also more than 20 cities with a population of more than one million. In the North China Plain, the grain output accounts for $18.4 \%$ of total national output; the output of cotton accounts for $40 \%$ of total national output; and the output of oil-bearing crops also accounts for a large proportion in China.

In 2006, the GDP per capita (GDPPC) in the North China Plain reached 19224.27 Yuan. According to the experience of industrialization and urbanization in the developed countries and districts, the urbanization development of the North China Plain has entered into the period of cluster development and the later period of industrialization development. Since the North China Plain is located in a vast plain area and the land use types are relatively unitary, the core problem of land use lies in the contradiction between the cultivated land 
TABLE 1: Land use structure of the North China Plain in various years (unit: ten thousand hectares).

\begin{tabular}{lcccccc}
\hline Land use type & 1988 & 1995 & 2000 & 2005 & 2010 & Change rate during 1988-2010 (\%) \\
\hline Cultivated land & 2448.81 & 2410.86 & 2402.01 & 2372.28 & 2346.51 & -4.18 \\
Forestry & 467.01 & 472.01 & 470.82 & 471.05 & 471.48 & 0.96 \\
Grassland & 375.12 & 363.34 & 363.48 & 356.25 & 355.51 & -5.23 \\
Water area & 310.09 & 312.74 & 315.28 & 317.84 & 321.02 & 3.53 \\
Built-up area & 1137.88 & 1187.64 & 1197.93 & 1237.09 & 1263.32 & 11.02 \\
Unused land & 40.20 & 32.50 & 29.58 & 24.59 & 21.25 & -47.12 \\
\hline
\end{tabular}

Change rate during $(R)$ 1988-2010 is calculated based on following formula: $R=(B-A) / A * 100 \% ; A$ represents the area of each type of land in 1988, and $B$ represents the area of each type of land in 2010.

protection and nonagricultural construction land [16]. The North China Plain is one of the important commodity grain bases in China, while its built-up area's expansion has taken up a large amount of high quality cultivated land resources, which poses threat to regional and national food security and ecological environment.

In the North China Plain, most researches focused on the impact of climate change on cultivated land. There are few researches of the response mechanism on grassland and builtup area, and only a few studies have explored the combined effects of climate change on the agricultural and forestry sectors. The North China Plain is China's traditional and important agricultural production base, and it is also a region where the population grows rapidly; economy and urbanization develop rapidly with obvious land use conversion, especially the transfer between cultivated land and nonagricultural land use [20]. Therefore, in this study, we selected the North China Plain as case study area to analyze the future land use structure changes under different scenarios. And based on an econometric model, we analyzed the effect of natural conditions (climate factors such as precipitation, temperature, etc.) and socioeconomic factors on land use structure changes. This study can provide reference for the decision making of the local land use planning, urbanization management, and land use management.

\section{Data}

2.1. Data. In this study, the information about land use structure and its changes was derived from the remote sensing images of the North China Plain in years 1988, 1955, 2000, 2005, and 2010 though the man-computer interactive interpretation (Table 1). And the information can be used as the basic data for analyzing the driving mechanism of land use structure changes.

According to the statistics in Table 1, in the North China Plain, cultivated land accounts for the largest share about $50 \%$, and built-up area, forestry, water area, and grassland overall occupy a certain proportion, which guaranteed the development of local farming, forestry, animal husbandry, side-line production, and fishery. From 1988 to 2010, there had been some changes in the macrostructure of land use; cultivated land and grassland decreased by $4.18 \%$ and $5.23 \%$, respectively. And along with the development of economy and expansion of urbanization, the built-up area increased by $11.02 \%$ from 1988 to 2010 . In addition, the change trends of each land use type during 1988-2010 are also not the same; cultivated and unused land always showed a trend of decrease, while water area and built-up area showed a continual trend of increase. The forestry overall increased with interval decrease from 1995 to 2000, and the grassland overall decreased with a slight interval increase from 1995 to 2000.

Moreover, the data used in this study include the basic geographic information data, socioeconomic data, and climate data that can affect land use structure changes. The basic geographic information data mainly include remote sensing data and biological geographical elements data. And the land use data and climate information are uniformly rasterized into $1 \mathrm{~km} \times 1 \mathrm{~km}$ grid cell. The land use data mainly come from remote sensing images interpretation during 1988-2010 [21], and then the information of interpreted raster data can be extracted from county level. And thus we derived the geographical elements information of each county, including temperature, precipitation. The concrete operations of data are mainly based on Arcgis9.3 and Stata10.0 platform, and the data eventually were prepared in the form of panel data for analyses [17].

In this study the socioeconomic data and climate data of 378 counties in the North China Plain were collected in 1988, 1995, 2000, 2005, and 2010 (Table 2). However, the land use data is of spatial data type. To make the land use data match with the statistic data of socioeconomic factors, the land use data should be aggregated into county level. And in order to increase the sample space, improve the degree of freedom, provide individual information, and make the estimated results more accurate, the data mentioned above were prepared into the format of panel data which integrated the cross-sectional data and the time-series data.

2.2. Scenarios. In this study, the basic settings of parameters for future scenarios are as follows: the average annual growth rate of annual per capita income is $7 \%$; the population in China should increase to $1.36,1.45$, and 1.5 billion in 2010, 2020 , and 2050, respectively. The data are derived from the forecast of National Planning and Chinese Academy of Social Sciences.

In this research, through investigating the rule of macroscopic land use structure changes during the past 20 years in the North China Plain, three scenarios were designed, namely, business as usual scenario (BAU), rapid economic growth scenario (REG), and coordinated environmental sustainability scenario (CES). The land use structure changes 
TABLE 2: Descriptive statistics of main variables at county level.

\begin{tabular}{|c|c|c|c|c|c|}
\hline Variable & Obs & Mean & Std. Dev. & Min & Max \\
\hline Population & 1633 & 614909.90 & 421749.10 & 63245 & 6600841 \\
\hline Annual per capita income (Yuan) & 1366 & 1959.64 & 2414.40 & 823 & 46739 \\
\hline Total grain output $(T)$ & 1392 & 294692.9 & 207261.60 & 0 & 2231531 \\
\hline Price index of agricultural products & 1935 & 104.12 & 3.30 & 101.30 & 108.40 \\
\hline Price index of forestry products & 1935 & 105.20 & 1.98 & 102.30 & 108.50 \\
\hline Price index of animal husbandry products & 1935 & 111.62 & 7.92 & 100.50 & 123.90 \\
\hline $\mathrm{NPP}$ (net primary productivity) $\left(\mathrm{gc} / \mathrm{m}^{2} \cdot \mathrm{y}\right)$ & 1933 & 352.66 & 85.39 & 143.74 & 827.50 \\
\hline Annual average precipitation (mm) & 1930 & 688.14 & 208.84 & 257.44 & 1562.09 \\
\hline Annual average temperature $\left({ }^{\circ} \mathrm{C}\right)$ & 1930 & 13.57 & 1.46 & 3.23 & 16.28 \\
\hline Land quality (dummy variable) & 1915 & 499.58 & 142.50 & 54.00 & 868.07 \\
\hline
\end{tabular}

The observations are different because of the data availability in several counties (387 counties $* 5$ periods).

TABLE 3: Regional trends in population and annual percapita income in the North China Plain assumed for the BAU, REG, and CES scenarios.

\begin{tabular}{lccccc}
\hline \multirow{2}{*}{ Scenario } & \multicolumn{5}{c}{ Year } \\
& 2010 & 2020 & 2030 & 2040 & 2050 \\
\hline Population & \multicolumn{5}{c}{ (Hundred million people) } \\
$\quad$ BAU & 2.48 & 2.51 & 2.54 & 2.57 & 2.6 \\
REG & 2.54 & 2.69 & 2.64 & 2.63 & 2.64 \\
CES & 2.42 & 2.52 & 2.45 & 2.35 & 2.33 \\
\hline Annual per capita income & & \multicolumn{5}{c}{ (Yuan) } \\
BAU & 3375.6 & 4537.8 & 5873.6 & 6974.3 & 7825.4 \\
REG & 3407.9 & 4769.8 & 6200.7 & 7443.3 & 8930.7 \\
CES & 3442.4 & 4625.4 & 5921.4 & 7220.5 & 8378.5 \\
\hline
\end{tabular}

Note: the annual per capita income was calculated and adjusted based on the consumer-price index of year 2000 to eliminate the effect of inflation.

of the North China Plain during 2010-2050 are simulated under the three different scenarios. These scenarios are storylines that represent different future developments regarding population growth, economic growth, and environmental sustainability (Table 3 ). We adopted the population and income assumptions of the three scenarios to develop associated projections of built-up area returns. We modified agricultural returns with projections of agricultural prices produced for each of these scenarios. Finally, we incorporated agricultural and forest yield changes into the scenarios. From 2010 to 2050, population and annual per capita income increase gradually and the population growth rate in the REG is the highest and about $1.3 \%$ higher than that in the CES scenarios. The REG scenario has higher annual per capita income, which is $24 \%$ higher than that in the CES scenario in 2050.

BAU Scenario was designed according to the socioeconomic conditions and the local development plan of the North China Plain, which can comprehensively and objectively reflect real conditions of local production activities and economic development.

REG Scenario and CES Scenario were designed with different conditions of economic development and ecological environmental sustainability to simulate the land use structure changes at county level. This study intends to
TABLE 4: National agricultural price indexes under the BAU, REG, and CES scenarios.

\begin{tabular}{lcccccc}
\hline \multirow{2}{*}{ Scenario } & \multicolumn{6}{c}{ Year } \\
& 2000 & 2010 & 2020 & 2030 & 2040 & 2050 \\
\hline BAU & 100 & 108 & 136.5 & 180.7 & 228.4 & 250.8 \\
REG & 100 & 109.7 & 147.4 & 188.7 & 230.1 & 267 \\
CES & 100 & 108.6 & 149 & 190.6 & 237.2 & 274.6 \\
\hline
\end{tabular}

simulate the land use structure changes, respectively, under different scenarios, among which the REG scenario is giving priority to economic development and the CES scenario is giving priority to ecological environmental sustainability and further provides reference for regional-level land use exploitation, planning, and management.

Most agricultural commodities are traded internationally. And, therefore, it makes sense to focus on how climate change will affect global agricultural prices; thus, this study applied the basic linked system (BLS), a computable general equilibrium model that represents all of the major economic sectors, including agriculture, together with the agroecological zones (AEZ) model, which can assess the effects of climate change on agricultural systems to analyze the impact of climate change. The regional price indexes of all crops in the three scenarios are shown in Table 4 . From the national point of view, the area of cultivated land will decrease year by year, the future mode of agricultural production will gradually transfer from cultivated land to grassland, and increase of built-up area will not bring small impact on cultivated land, so the national and regional agricultural price index is rising constantly in the future (Table 4). The national agricultural price index has obvious rising trend year by year, and it is significantly higher under the REG and CES scenarios than that under the BAU scenario, which means that in order to guarantee the rapid economic growth and the sustainable development of ecological environment, it will inevitably lead to the changes of land use structure and further affect the changes of industrial structure and product price.

\section{Methodology}

As to the methods used to project land use structure under the BAU, REG, and CES scenarios, in the first subsection, we 
discuss the land-use simulation model. The key driver of land use structure changes in the projection model is county-level net profits of cultivated land, grassland, forestry, and builtup area. These variables are modified in the three scenarios according to assumed changes in population and annual per capita income and to predicted changes in regional agricultural prices, NPP, and forest carbon. And in the subsequent subsections, we discuss how these projections are scaled down to the county level and linked to the net profits.

3.1. Land-Use Simulation Model. In this study, based on the econometric model that Haim et al. used to study the relationship between climate change and future land use changes in US, the land-use simulation model is developed through adjusting the variables that affect the net profit of each land use type [2]. In the model, the change of the overall land system with various land use types can be simulated, and it allows transfers of different land use types. This study applied the historical data of the North China Plain to estimate the land owners' response to economic benefits and further make decisions on land use allocation. The county-level net profits of cultivated land, forestry, grassland, and built-up area are regarded as the main driving factors of land use structure changes, and the net profits are calculated synthetically based on population, annual per capita income, agricultural prices, NPP, and so forth. Climate change can indirectly affect the net profits through causing the change of some factors, and according to the principle of maximum benefits, it will affect land use allocation.

In this model, the area of each land use type is the dependent variable, and the net profit and quality of each land use type are independent variables. The net profit variables provide the link between different land use types, which can be described in detail as follows.

The general equation for the net profit in county $c$ is as

$$
\mathrm{NP}_{m c}=\sum_{m} \omega_{m c} p_{m c} q_{m c}-\sum_{m} \omega_{m c} c_{m c}
$$

where $\omega_{m c}$ is the net profits for commodity type $m$ in county $c, p_{m c}$ is the per-unit price for commodity type $m$ in county $c, q_{m c}$ is the per-acre average yield of commodity type $m$ in county $c$, and $c_{m c}$ is the per-hectare cost of producing commodity type $m$ in county $c$. Thus, the net profits of different land use types can be calculated as the income of all the products minus the cost.

In the model, it is assumed that the land owners' expected values of the net profits of land are fixed, and they would change the land use type in order to get the maximum net profits. The net profits include deterministic and stochastic components; the deterministic components include countylevel net profits, land quality, and interaction between the two variables, and the stochastic components are estimated through the nested logit model according to the distribution hypothesis [20]. In this study, four main types of land use are taken into consideration, which are cultivated land, forestry, grassland, and built-up area. The probabilities of the transfer of different types of land use can be calculated based on the econometric model shown in (2), in which the independent variables and estimated parameters are incorporated to calculate the probabilities:

$$
P_{i j k}^{t}=P\left(\varepsilon_{j k}, \mathrm{NP}_{i}^{t}, L Q_{i}\right),
$$

where $P_{i j k}^{t}$ is the probability that the land use type $j$ will be transferred to land use type $k$ in region $i$ during the research period, $\varepsilon_{j k}$ is the vector of estimated parameters, and $L Q_{i}$ is the dummy variable that indicates land quality of region $i$.

Scenario simulations are performed at county level, considering year 1988 as the baseline, and, for simplicity, years 1988, 1995, 2000, 2005, and 2010 are noted as $t=0,1,2,3,4$,

$$
S_{i j k}^{t+1}=\sum_{k} P_{i j k}^{t} \cdot S_{i k t}
$$

where $S_{i k}^{t}$ is the area of land use type $j$ in region $i$ at time $t$, and we can get the sequence of transfer probabilities with (2), and then future land use allocation can be calculated. The land use structure changes from time $t$ to time $t+1$ indicate the change of supply of land products and services and further indicate the change of net profits and prices of all land use types. In this study, the prices of land products of cultivated land, forestry, grassland, and built-up land are regarded as exogenous variables.

As the area of each type of land use $\left(S_{i j 0}\right)$ in baseline year was known, the land use structure changes till 2050 can be simulated based on (3). The transfer probability $P_{i k j}^{t}$ can be derived from (2), and $P_{i k j}^{t}$ is a function of county-level net profit. Thus, once we get the county-level net profit, the future land use structure changes can be simulated.

\subsection{Estimation of Net Profits}

Net Profit of Built-Up Area. According to the standard urban land rent theory, population and income growth are the two main determinants of the value of urban land [18]. Based on statistical model using county-level panel data, the net profit of built-up area as the dependent variable can be linked with the population and income as independent variables at county level. And according to the theory, population and annual per capita income are positively correlated with the built-up area value. High annual per capita income increases the demand for housing and high population growth increases the price of habitable land. So, we can choose population and annual per capita income as two indicators to simulate and predicate the future net profit of built-up area.

Net Profit of Cultivated Land. According to (1), using the price index of agricultural products $P_{m c}$ released by National Bureau of Statistics, the net profit of cultivated land can be calculated. Considering the condition of marked economy in China, it is reasonable to apply the nation price index to county-level estimation, and it is the same to the countylevel price index of forestry products and animal husbandry products.

Net Profits of Forestry and Grassland. Based on the MAPSS model, it was assumed that the changes of forestry products 
and animal husbandry products were positively correlated with NPP. Through optimal management measures, the NPP of forestry and grassland can reach the maximum value. And the NPP was calculated based on leaf area index (LAI) and normalized difference vegetation index (NDVI).

3.3. Validation of the Model. In order to validate the accuracy of the model, that is, to verify whether the simulation results can meet with the actual situation of land use, based on the historic data of land use, we do the validation as follows. Based on the model and actual land use data in 2005, we simulate the land use structure in 2010 , then calculate the deviance between the actual land use structure in 2010 and the simulated land use structure, and thus measure the accuracy of the model, as shown in

$$
D_{i, t}=\frac{\widehat{Y}_{i, t}-Y_{i, t}}{Y_{i, t}} \times 100 \%,
$$

where $D_{i, t}$ is the area deviance of land use type $i$ at time $t, \widehat{Y}_{i, t}$ is the simulated area of land use type $i$ at time $t$, and $Y_{i, t}$ is the actual area of land use type $i$ at time $t$.

The validation results showed that the deviance of forestry and grassland was $\pm 4 \%$ and $\pm 3 \%$ respectively. While cultivated land and built-up area account for larger shares, the deviance of them is relatively high, but the overall deviance was still controlled within $8 \%$. Thus, the model can be regarded as robust and can be used to simulate the future land use.

\section{Results}

In this study, we established the county-level net return models of cultivated land, forestry, grassland, and built-up area. And various factors that have effects on the net returns were synthetically incorporated into the basic land use structure change model. Through the analysis of the historical data, land use structure change model can quantitatively determine the effect degrees of various factors on the land use structure changes. Then, as to the simulation of future land use structure, based on the effect degrees of the factors, such as population, annual per capita income, and price index, the future land use structure changes can be simulated under different scenarios.

The macroscopic change of the land use structure during 2010-2050 was simulated under different scenarios, with the water area and unused land integrated into other lands since it is difficult to evaluate them. As to the simulation of land use scenarios, integrating all the factors that can affect the net returns, according to the assumption of the changes of population and annual per capita income, expected agricultural prices, and grassland production, the future land use structure changes can be simulated from 2010 to 2050.

Under the BAU scenario (Figure 2), cultivated land and built-up area are still the main land use types, but cultivated land tends to decrease year by year, and built-up area tends to increase year by year, which is the inevitable requirement of economic development. By 2050, the cultivated land still accounts for the largest proportion. The forestry generally

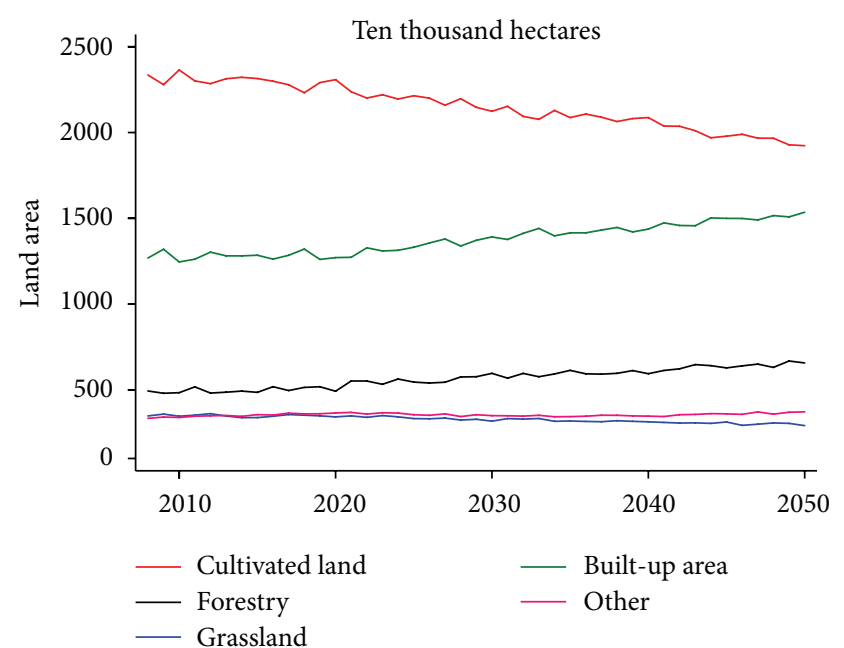

FIGURE 2: Structure changes of land use under BAU scenario.

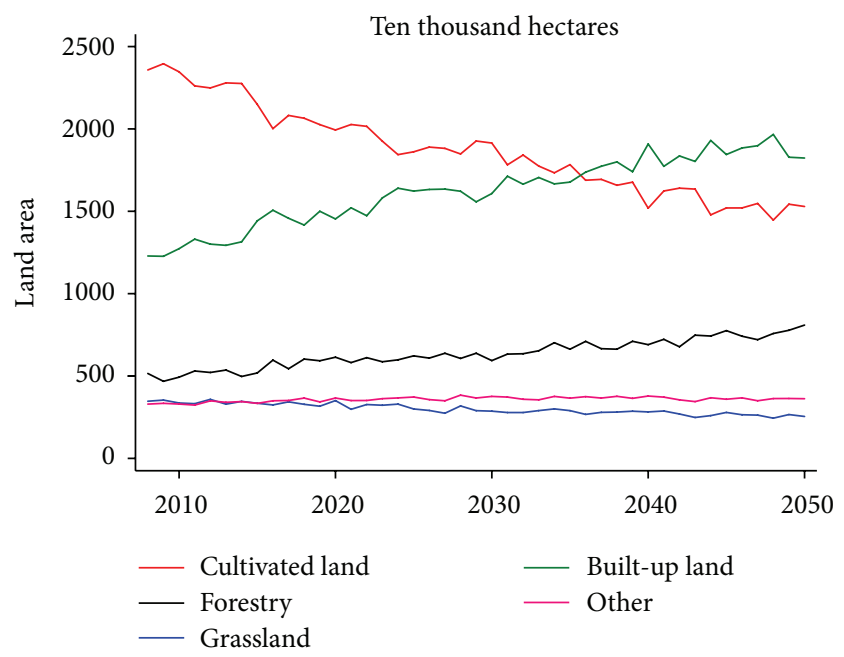

FIGURE 3: Structure changes of land use under REG scenario.

shows a growing trend; the grassland overall shows a trend of decrease; the change of both of land use types is not obvious; and the amount of forestry and grassland is relatively stable.

Under the REG scenario (Figure 3), during 2010-2050, the area of cultivated land decrease, from 2400 ten thousand hectares to 1500 ten thousand hectares, reducing by $37.5 \%$. However, there has been a rapid growth in built-up area, the area of which increases from 1250 ten thousand hectares to 2000 ten thousand hectares. The growth rate of built-up area is much higher than that under the BAU scenario (Figure 2) and CES scenario (Figure 4). However, the area of forestry shows a trend of fluctuations with slow increase and the area of grassland decreases year by year with small amplitude.

Under the CES scenario, we give priority to the protection of development of ecological environmental sustainability. According to the simulation results, the area of cultivated land decreases significantly, while the area of built-up area and woodland area increases year by year, and the area of grassland also shows a trend of decrease, but the trend is 


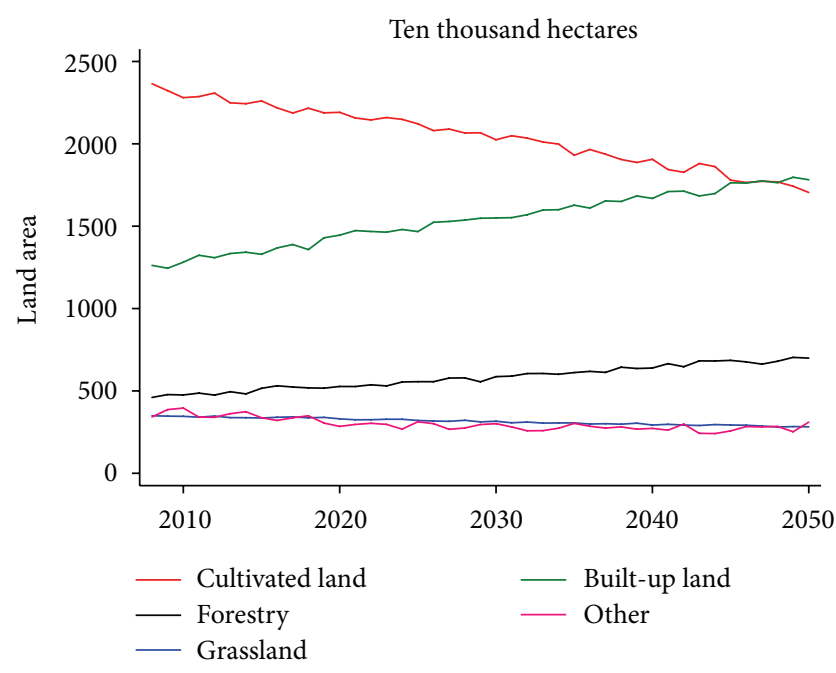

FIGURE 4: Structure changes of land use under CES scenario.

not obvious. The decreasing trend of cultivated land and the expansion trend of built-up area can reach stable balance until 2050 , and the area of the forestry continues to increase to maintain the sustainable development of ecological environment.

In general, with the improvement of economic growth rate, the built-up area is increasing year by year, and the decrement rate of cultivated land is also increasing. Under the REG and CES scenarios, the proportion of built-up area in the land system is more than that of the cultivated land by 2050 . And under the three different economic growth scenarios, the forestry overall shows a trend of increase, and the growth rate of forestry speeds up as economic growth speeds up. And the grassland overall shows a trend of decrease under the three scenarios.

\section{Conclusions}

The North China Plain is one of the agricultural production bases in China, which is in the important period of increasing population, developing economy, and accelerating urbanization process. In this paper, we applied econometric model to analyze the mechanism of county-level land use structure changes, then simulated the changes of land use structure from 2010 to 2050 under three scenarios, quantitatively revealed the relationship between the land use structure changes and the driving factors, and realized the simulation and scenario analysis on structural changes of land use. This relatively sophisticated county-level land use structure changes simulation method can be applied in other regions, and the conclusions can provide reference for decision making of regional-level land exploitation, planning, and management.

First, comparing the simulation results of future land use structure changes in the North China Plain of BAU, REG, and CES scenarios, the competition laws among land use types under the synthesized effects of various driving factors can be analyzed. Under the BAU scenario, each type of land experience expansion and shrinkage to some extent over time, among which, the cultivated land has an obvious trend of decrease and the built-up area has an obvious trend of increase. And under the REG and CES scenarios, since the economic growth rates are different, the extents of expansion and shrinkage of different land use types are also different.

Second, the built-up land overall shows a trend of increase under the three scenarios, with its area increasing from 1260 ten thousand hectares in 2010 to 1500 ten thousand hectares, 1910 ten thousand hectares, and 1820 ten thousand hectares in 2050 under the BAU, REG, and CES scenarios, respectively. Under the REG scenario, the significant increase of the built-up land reflects that the rapid economic growth can lead to the increase in net return of built-up area and it is important to note that the growth rate of built-up area may be overestimated since the endogenous driving factor urbanization is not taken into consideration. There has been a view that, with the expansion of built-up area, the net return of built-up area will decline, thus, to limit the continual expansion of built-up area. In addition, the increase in the net return of built-up area could lead to the increase of urban housing density and further affect land use structure, while the housing factor is also not taken into consideration in this model. Thus, the absence of these factors may limit the accuracy of the simulation results of land use structure in these models.

Third, the structural change trends of land use under the three scenarios are relatively consistent, with cultivated land showing a trend of decrease and built-up area showing a trend of increase. It indicates that urbanization in the North China Plain is one of the main driving factors of land use structure changes. According to the simulation results, cultivated land, as the main land use type in the North China Plain, accounting for the largest proportion, decreases with the improvement of economic growth. Under the REG scenario, the area of cultivated land will be less than that of built-up land by 2050 .

Finally, the simulation results of land use structure changes under the three scenarios can provide significant reference for making land use planning and sustainable development strategy of government. On the whole, the cultivated land will decrease and built-up area will increase with the economic development, which may lead to contradiction between cultivated land, food security, and improvement in our living standard. So, more attentions should be paid to the trade-off between the urban expansion and food security, including the land consolidation and rehabilitation and compensation mechanism for protecting cultivated land.

\section{Discussions}

We have projected land use structures at regional scale under three scenarios. Our method involves linking projections from global integrated assessment models (IAMs) of agricultural price and agricultural and forest yields to county-level measures of net returns of alternative use and then using an econometric model of land use structure changes to make associated projections of land use structure. We also adopt assumed trends in population and annual per capita income 
and use these to project future net returns to urbanization. Projected land areas under the CES and REG scenarios are compared to those under the BAU scenario that assumes historical trends in agricultural prices and agricultural and forest yields.

On regional level, urbanization is found to be a key driver of land use structure changes. The demographic changes resulting in urbanization have larger effects on land use future structure than on the land use net returns change with the agricultural and forest sectors. Although we have achieved some of the steps in the projected land use area in future, much work remains to be done. As noted above, additional work is needed on the effect of yield variation on land use decisions. Effects of climate change on crop and timber prices also need attention. Finally, the largest task will be to model the feedback from regional outcomes to IAMs. This will ensure consistency between predictions of climate change at global and regional scales. The study will also give some enlightenment on the land use planning of stakeholders.

\section{Conflict of Interests}

The authors declare that there is no conflict of interests regarding the publication of this paper.

\section{Acknowledgments}

This research was supported by the Key Project funded by the National Natural Science Foundation of China (Grant no. 41071343), National Key Programme for Developing Basic Science in China (Grant no. 2010CB950900), and the Key Projects in the National Science \& Technology Pillar Program (Grant no. 2013BAC03B03).

\section{References}

[1] J. A. Foley, R. DeFries, G. P. Asner et al., "Global consequences of land use," Science, vol. 309, no. 5734, pp. 570-574, 2005.

[2] D. Haim, J. Alig, J. Plantinga, D. Haim, and J. Sohngen, "Climate change and future land use in the united states: an economic approach," Climate Change Economics, vol. 2, no. 1, pp. 27-51, 2011.

[3] Q. Jiang, X. Deng, H. Yan, D. Liu, and R. Qu, "Identification of food security in the mountainous guyuan prefecture of China by exploring changes of food production," Journal of Food, Agriculture and Environment, vol. 10, no. 1, pp. 210-216, 2012.

[4] W. Schlenker, W. M. Hanemann, and A. C. Fisher, "Will U.S. agriculture really benefit from global warming? Accounting for irrigation in the hedonic approach," The American Economic Review, vol. 95, no. 1, pp. 395-406, 2005.

[5] O. Deschênes and M. Greenstone, "The economic impacts of climate change: evidence from agricultural output and random fluctuations in weather," The American Economic Review, vol. 97, no. 1, pp. 354-385, 2007.

[6] W. Schlenker and M. J. Roberts, "Nonlinear temperature effects indicate severe damages to U.S. crop yields under climate change," Proceedings of the National Academy of Sciences of the United States of America, vol. 106, no. 37, pp. 15594-15598, 2009.
[7] J. Perez-Garcia, L. A. Joyce, A. D. Mcguire, and X. Xiao, "Impacts of climate change on the global forest sector," Climatic Change, vol. 54, no. 4, pp. 439-461, 2002.

[8] B. Sohngen, R. Mendelsohn, and R. Sedjo, "A global model of climate change impacts on timber markets," Journal of Agricultural and Resource Economics, vol. 26, no. 2, pp. 326-343, 2001.

[9] R. C. Izaurralde, N. J. Rosenberg, R. A. Brown, and A. M. Thomson, "Integrated assessment of Hadley Center $\left(\operatorname{HadCM}_{2}\right)$ climate-change impacts on agricultural productivity and irrigation water supply in the conterminous United States-part II: regional agricultural production in 2030 and 2095," Agricultural and Forest Meteorology, vol. 117, no. 1-2, pp. 97-122, 2003.

[10] D. B. Lobell and C. B. Field, "Estimation of the carbon dioxide $\left(\mathrm{CO}_{2}\right)$ fertilization effect using growth rate anomalies of $\mathrm{CO}_{2}$ and crop yields since 1961," Global Change Biology, vol. 14, no. 1, pp. 39-45, 2008.

[11] R. Qu, X. Cui, H. Yan, E. Ma, and J. Zhan, "Impacts of land cover change on the near-surface temperature in the North China Plain," Advances in Meteorology, vol. 2013, Article ID 409302, 12 pages, 2013.

[12] S. Sirohi and A. Michaelowa, "Sufferer and cause: Indian livestock and climate change," Climatic Change, vol. 85, no. 34, pp. 285-298, 2007.

[13] M. Herrero, P. K. Thornton, P. Gerber, and R. S. Reid, "Livestock, livelihoods and the environment: understanding the trade-offs," Current Opinion in Environmental Sustainability, vol. 1, no. 2, pp. 111-120, 2009.

[14] T. Garnett, "Livestock-related greenhouse gas emissions: impacts and options for policy makers," Environmental Science and Policy, vol. 12, no. 4, pp. 491-503, 2009.

[15] C. Nobre, P. Sellers, and J. Shukla, "Amazonian deforestation and regional climate change," Journal of Climate, vol. 4, no. 10, pp. 957-988, 1991.

[16] X. Deng, H. Su, and J. Zhan, "Integration of multiple data sources to simulate the dynamics of land systems," Sensors, vol. 8, no. 2, pp. 620-634, 2008.

[17] X. Deng, F. Yin, Y. Lin, Q. Jin, and R. Qu, "Equilibrium analyses on structural changes of land uses in Jiangxi Province," Journal of Food, Agriculture and Environment, vol. 10, no. 1, pp. 846-852, 2012.

[18] D. R. Capozza and R. W. Helsley, "The fundamentals of land prices and urban growth," Journal of Urban Economics, vol. 26, no. 3, pp. 295-306, 1989.

[19] Q. Jiang, X. Deng, J. Zhan, and S. He, "Estimation of land production and its response to cultivated land conversion in North China Plain," Chinese Geographical Science, vol. 21, no. 6, pp. 685-694, 2011.

[20] L. Jiang, X. Deng, and K. C. Seto, "Multi-level modeling of urban expansion and cultivated land conversion for urban hotspot counties in China," Landscape and Urban Planning, vol. 108, no. 2-4, pp. 131-139, 2012.

[21] R. S. Yin, Q. Xiang, J. T. Xu, and X. Z. Deng, "Modeling the driving forces of the land use and land cover changes along the upper yangtze river of China," Environmental Management, vol. 45, no. 3, pp. 454-465, 2010. 

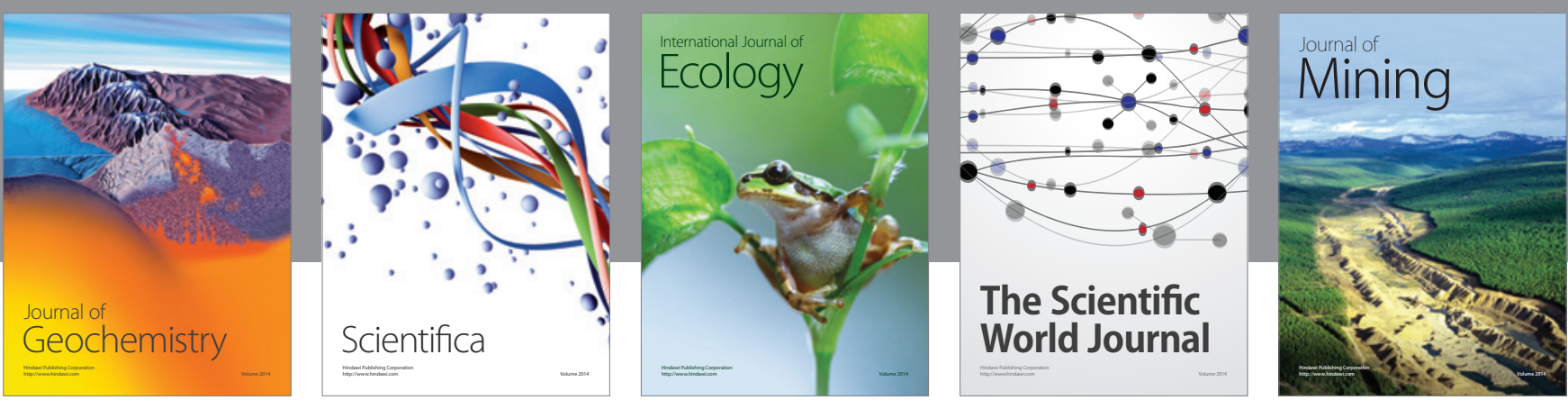

The Scientific World Journal
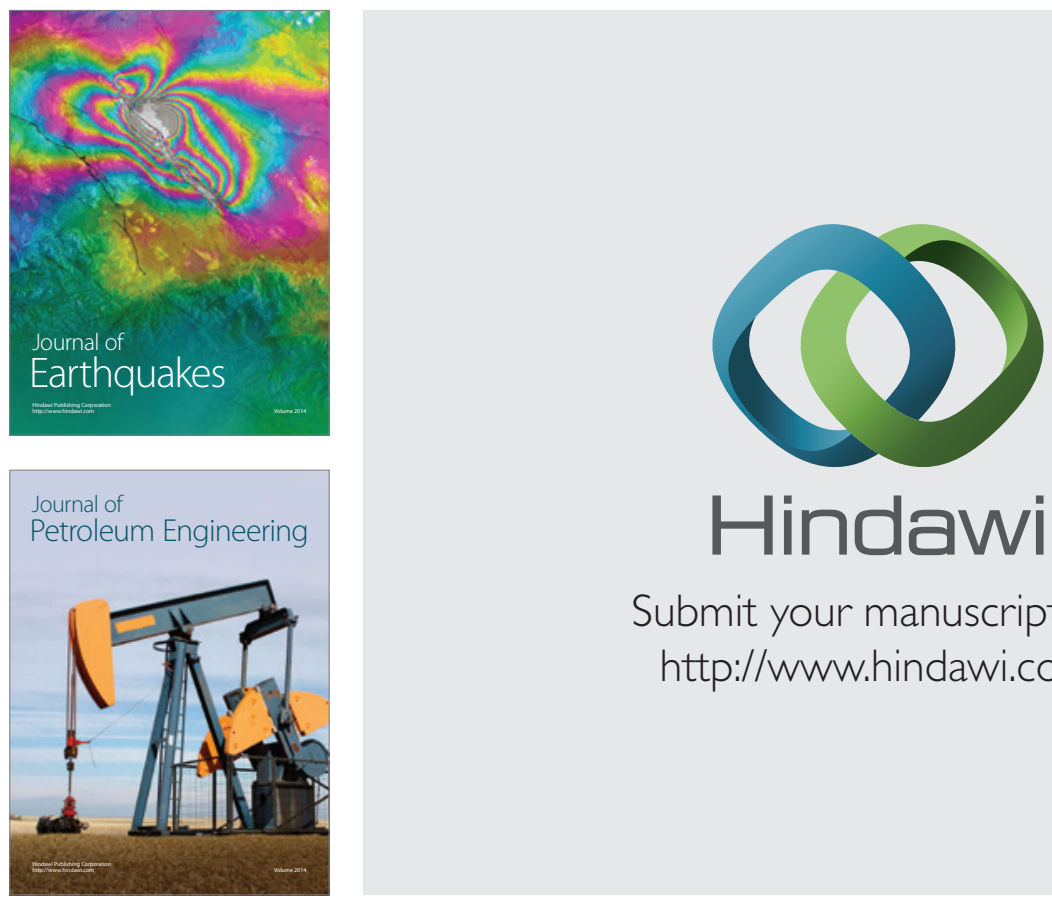

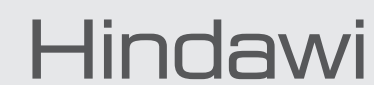

Submit your manuscripts at

http://www.hindawi.com
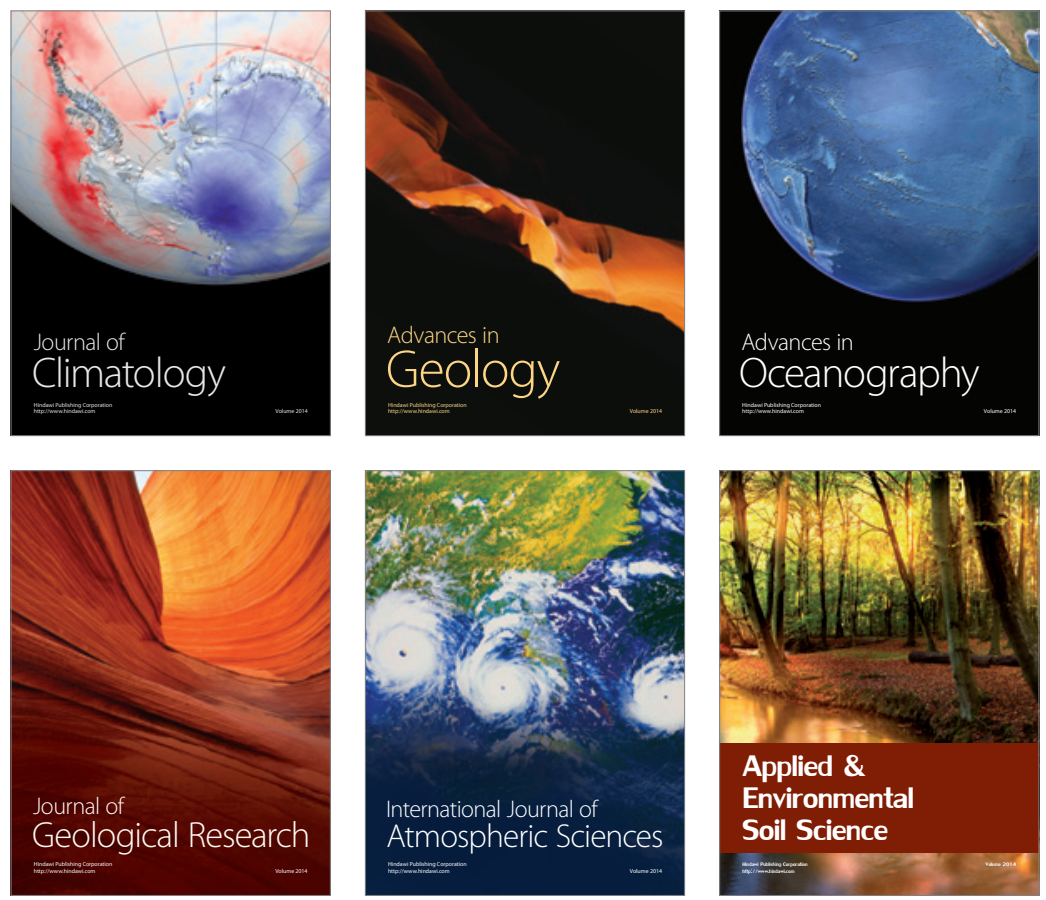
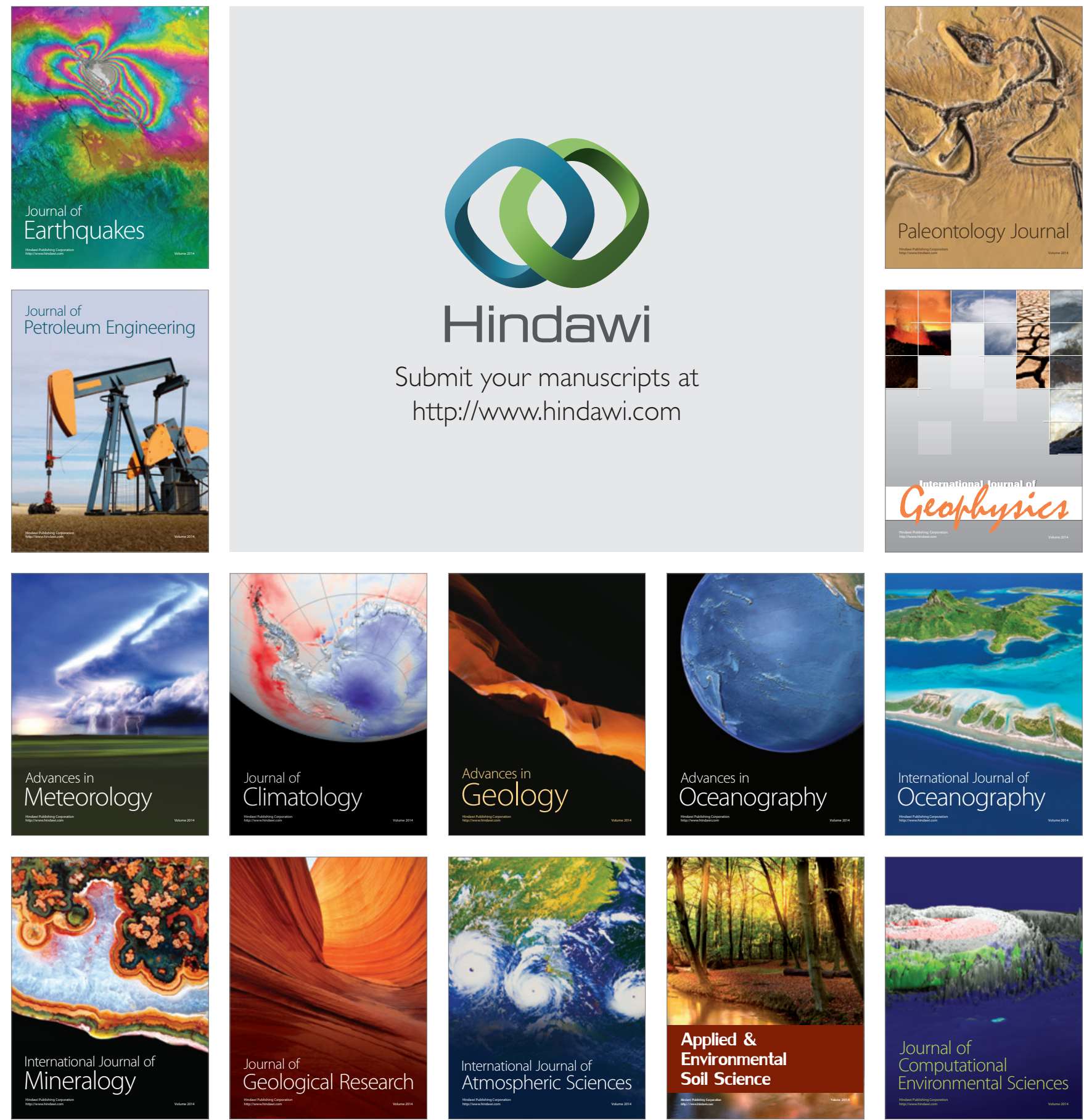